\title{
Propofol has delayed myocardial protective effects after a regional ischemia/reperfusion injury in an in vivo rat heart model
}

\author{
Il Woo Shin ${ }^{1,3}$, In Seok Jang ${ }^{2}$, Seung-Hwa Lee ${ }^{1}$, Ji-Seok Baik ${ }^{1}$, Kyeong-Eon Park ${ }^{1}$, Ju-Tae Sohn ${ }^{1,3}$, \\ Heon Keun Lee ${ }^{1,3}$, and Young Kyun Chung ${ }^{1,3}$ \\ Departments of ${ }^{1}$ Anesthesiology and Pain Medicine,${ }^{2}$ Thoracic Surgery, ${ }^{3}$ Institute of Health Sciences, Gyeongsang National University \\ College of Medicine, Jinju, Korea
}

Background: It is well known that propofol protects myocardium against myocardial ischemia/reperfusion injury in the rat heart model. The aim of this study was to investigate whether propofol provides a protective effect against a regional myocardial ischemia/reperfusion injury in an in vivo rat heart model after $48 \mathrm{~h}$ of reperfusion.

Methods: Rats were subjected to 25 min of left coronary artery occlusion followed by $48 \mathrm{~h}$ of reperfusion. The sham group received profopol without ischemic injury. The control group received normal saline with ischemia/ reperfusion injury. The propofol group received profopol with ischemia/reperfusion injury. The intralipid group received intralipid with ischemia/reperfusion injury. A microcatheter was advanced into the left ventricle and the hemodynamic function was evaluated. The infarct size was determined by triphenyltetrazolium staining. The serum level of cardiac troponin-I (cTn-I) was determined by ELISA (enzyme-linked immunosorbent assay).

Results: Propofol demonstrated protective effects on hemodynamic function and infarct size reduction. In the propofol group, the $+\mathrm{dP} / \mathrm{dt}_{\max }(\mathrm{P}=0.002)$ was significantly improved compared to the control group. The infarct size was $49.8 \%$ of the area at risk in the control group, and was reduced markedly by administration of propofol to $32.6 \%$ in the propofol group $(\mathrm{P}=0.014)$. The ischemia/reperfusion-induced serum level of cTn-I was reduced by propofol infusion during the peri-ischemic period $(\mathrm{P}=0.0001)$.

Conclusions: Propofol, which infused at clinically relevant concentration during the peri-ischemic period, has delayed myocardial protective effect after regional myocardial ischemia/reperfusion injury in an in vivo rat heart model after $48 \mathrm{~h}$ of reperfusion. (Korean J Anesthesiol 2010; 58: 378-382)

Key Words: Ischemia/reperfusion injury, Myocardium, Propofol.

Received: October 19, 2009. Revised: November 25, 2009. Accepted: March 2, 2010.

Corresponding author: Young Kyun Chung, M.D., Department of Anesthesiology and Pain Medicine, Gyeongsang National University College of Medicine, 92, Chilam-dong, Jinju 660-280, Korea. Tel: 82-55-750-8584, Fax: 82-55-750-8142, E-mail: ykchung@nongae.gsnu.ac.kr

This work was supported by the Korea Research Foundation Grant funded by the Korean Government (MOEHRD) (KRF-2007-331-E00170).

(C) This is an open-access article distributed under the terms of the Creative Commons Attribution Non-Commercial License (http:// creativecommons.org/licenses/by-nc/3.0/), which permits unrestricted non-commercial use, distribution, and reproduction in any medium, provided the original work is properly cited. 


\section{Introduction}

Propofol has a myocardial protective effect through a range of mechanisms, such as oxygen free radical scavenging [1-3], blocking of the calcium channel by inhibiting the L-type calcium channel [4,5], and inhibiting neutrophil activation [6,7]. The myocardial protective effect of propofol has been identified by a variety of methods using an ischemia/reperfusion (I/R) injury model $[1-3,7,8]$. However, some technical problems make it difficult to perform a long-term follow-up of the myocardial protective effect. Some reports have shown that myocardial infarct size and neutrophil adherence peak at 24 and $48 \mathrm{~h}$, respectively, after an I/R injury $[9,10]$. During the late reperfusion period, myocardial apoptotic cell death develops progressively until $72 \mathrm{~h}$ [10]. Therefore, long-term observations will be needed to determine whether myocardial protection is a temporary or sustained effect [11-13].

In this study, a regional myocardial I/R injury in an in vivo rat heart model was used to determine the effects of a clinically relevant propofol concentration during the periischemic period of anesthesia. After $48 \mathrm{~h}$ of reperfusion, the hemodynamic function, infarct size, and cardiac troponin-I (cTn-I) level were checked to determine whether propofol had a delayed myocardial protective effect against a regional myocardial I/R injury in an in vivo rat heart model.

\section{Meterials and Methods}

\section{Animal preparation}

Male Sprague-Dawley rats weighing between 220 and $240 \mathrm{~g}$ were used. All animals were maintained in accordance with the Guidelines for the Care and Use of Laboratory Animals published by the US National Institutes of Health in 1996.

The animals received general anesthesia with an intramuscular injection of $50 \mathrm{mg} / \mathrm{kg}$ of ketamine (Ketamine $\mathrm{Hcl}^{\circledR}$, Huons, Seoul, South Korea) and $3 \mathrm{mg} / \mathrm{kg}$ of zylazine (Rompun ${ }^{\circledR}$, Bayer, Seoul, South Korea). The rats were judged to be awake from the anesthesia once their tails moved during the procedure, and then $25 \mathrm{mg} / \mathrm{kg}$ of ketamine and $1.5 \mathrm{mg} / \mathrm{kg}$ of zylazine were injected to maintain the level of anesthesia. After anesthesia was induced, a heparin-treated $24 \mathrm{G}$ catheter was inserted into the femoral vein, and each drug was infused according to the protocol. The trachea was intubated, and the rats were ventilated mechanically (tidal volume: $8 \mathrm{ml} / \mathrm{kg}$, respiratory rate: 80 strokes/min) with ambient air using a volume-controlled rodent ventilator (Harvard Rodent Ventilator Model 607, Harvard, Holliston, MA, USA). The arterial blood $\mathrm{pH}$ and gases were maintained within normal physiological limits ( $\mathrm{pH}: 7.3-$ 7.4, $\mathrm{PaCO}_{2}: 30-40 \mathrm{mmHg}, \mathrm{PaO}_{2}: 60-100 \mathrm{mmHg}$ ).
A paramedian sternotomy was performed, and the pericardium was opened to expose the heart. For the I/R experiments, a 4-0 black silk, nonabsorbable suture was passed around the left coronary artery (LCA) territory to induce regional myocardial ischemia. The coronary artery was occluded by pulling a snare through a small vinyl chloride tube and clamping it with a mosquito hemostat. Reperfusion was achieved by releasing the clamp. Myocardial ischemia was confirmed by the appearance of regional epicardial cyanosis over the myocardial surface and by arrhythmia. After 25 min of ischemia, the myocardium was reperfused by loosening the snare, which was maintained for $48 \mathrm{~h}$ of reperfusion. Successful reperfusion was confirmed by the disappearance of epicardial cyanosis and the production of epicardial hyperemia and arrhythmia after releasing the snare. The body temperature was monitored with a rectal thermometer and maintained at $36-38^{\circ} \mathrm{C}$ using a heating pad.

\section{Experimental protocols}

Sixty-four rats were divided randomly into four groups. The sham group received a bolus infusion of $2.5 \mathrm{mg} / \mathrm{kg}$ of profopol (Fresofol $^{\circledR} 2 \%$, Fresenius Kabi, Homburg, Germany) followed by a continuous propofol infusion at a rate of $200 \mu \mathrm{g} / \mathrm{kg} / \mathrm{min}$, which was maintained until $30 \mathrm{~min}$ after the sham operation. The LCA was not occluded. The control group received $0.3 \mathrm{ml}$ of normal saline intravenously followed by a continuous infusion of normal saline at a rate of $1.5 \mathrm{ml} / \mathrm{h}$. The propofol group received a bolus infusion of $2.5 \mathrm{mg} / \mathrm{kg}$ of profopol followed by a continuous propofol infusion at a rate of $200 \mu \mathrm{g} / \mathrm{kg} / \mathrm{min}$. The intralipid group received a bolus infusion of $0.3 \mathrm{ml}$ of $2 \%$ intralipid (20\% Intralipid ${ }^{\circledR}$, Fresenius Kabi, Sweden) followed by a continuous infusion of $2 \%$ intralipid at a rate of $1.5 \mathrm{ml} / \mathrm{h}$. A 25 min LCA occlusion was produced followed by $48 \mathrm{~h}$ of reperfusion. Each drug was administered intravenously 5 min before the ischemic insult, and continuous drug infusion was maintained until 5 min after reperfusion.

An additional experiment was performed when a rat died during an experiment or during the postexperimental care period. An additional experiment was required for five, zero, six, and four rats in the control, sham, propofol, and intralipid groups, respectively. Two and four rats in the control and intralipid groups, respectively, required additional anesthesia. The hemodynamic function and infarct weight were checked in 10 rats of each group. The cardiac troponin-1 (cTn-I) level was also checked in six rats from each group.

\section{Measuring hemodynamic variables and myocardial contractility}

After the $48 \mathrm{~h}$ reperfusion, the rats were anesthetized with 
$25 \mathrm{mg} / \mathrm{kg}$ of ketamine and $1.5 \mathrm{mg} / \mathrm{kg}$ of xylazine. The right common carotid artery was cannulated with a 2-Fr Millar catheter (Model SPR-407, Millar Instruments Inc., Houston, TX, USA) and advanced into the left ventricle (LV) to measure heart rate (HR), left ventricular systolic pressure (LVSP), left ventricular end diastolic pressure (LVEDP), the peak rate of intraventricular pressure increase $\left(+\mathrm{dP} / \mathrm{dt}_{\max }\right)$, and the peak rate of intraventricular pressure decrease $\left(-\mathrm{dP} / \mathrm{dt}_{\max }\right)$. The systolic and diastolic pressures were checked after repositioning the catheter to the ascending aorta.

\section{Determining the areas at risk and infarct size}

After analyzing hemodynamic function, the LCA was occluded again, and $1 \mathrm{ml}$ of $2 \%$ Evans blue dye was injected into the pulmonary artery to determine the areas at risk (AAR). The perfused myocardium was stained with Evans blue dye, whereas the occluded vascular bed was not. The atrium, right ventricle, and major vessels were removed from the heart, and the AAR was separated from the non-ischemic area. The AAR was cut into small pieces and incubated in $0.5 \%$ 2,3,5-triphenyltetrazolium chloride (TTC) at $37^{\circ} \mathrm{C}$ for 15 min. The non-infarcted myocardium was stained a deep red color with TTC, and the infarcted area (IA) remained a pale yellow. The sections were fixed for $24 \mathrm{~h}$ in $2 \%$ formalin, and the LV, AAR, and IA weights were determined. The AAR and IA were expressed as a percentage of the LV and AAR weights, respectively.

\section{Measuring cTn-I}

Twenty-four rats were assigned to the four groups to measure cTn-I levels. The thoracic cavity was opened to expose the heart and collect a $2 \mathrm{ml}$ blood sample from the right ventricle. The serum was collected and stored at $-75^{\circ} \mathrm{C}$ until analysis. The serum cTn-I level was determined using an enzyme linked immunosorbent assay kit from Life Diagnostics (cat. no. 20102-HS, West Chester, PA, USA). The cTn-I activity was detected by spectrophotometry (Infinite ${ }^{\circledR}$ F200, Tecan Group Ltd., Mönnedorf, Switzerland) at $460 \mathrm{~nm}$ after reacting the serum sample on a cTn-I antibody-coated plate.

\section{Statistical analysis}

All values are expressed as the mean \pm SD. All statistical analyses were performed using SPSS software (ver. 12.0 for Windows, SPSS Inc., Chicago, IL, USA). The differences between groups were evaluated using a Friedman one-way analysis of variance and a post hoc Tukey's multiple comparison test. Statistical significance was defined as $\mathrm{P}<0.05$.

\section{Results}

\section{Hemodynamic function following I/R injury}

The hemodynamic measurements recorded after $48 \mathrm{~h}$ of reperfusion revealed LV dysfunction, as demonstrated by the increased LVEDP $(\mathrm{P}=0.01)$ and decreased LVSP $(\mathrm{P}=$ $0.01),+d P / d t_{\max }(P=0.0001)$, and $-d P / d t_{\max }(P=0.0001)$ in the control group compared to the sham group. Propofol significantly inhibited the decrease in $+\mathrm{dP} / \mathrm{dt}_{\max }$ compared to the control group $(\mathrm{P}=0.002)$ and intralipid group $(\mathrm{P}=0.01)$ (Table 1).

\section{Myocardial infarct size}

No significant differences between the three groups were observed in the AAR/LV induced by occluding the LCA territory. The IA weights in the control, propofol, and intralipid groups were $0.12 \mathrm{~g}, 0.08 \mathrm{~g}(\mathrm{P}=0.031$ vs. control group), and $0.09 \mathrm{~g}$, respectively. The IA/AAR in the control, propofol, and intralipid groups was $49.8 \%, 32.6 \%$ ( $\mathrm{P}=0.014$ vs. control group), and $33.4 \%$ ( $\mathrm{P}=0.045$ vs. control group), respectively. No significant differences in IA weight and IA/AAR were found between the propofol and intralipid groups (Table 2).

Table 1. Hemodynamic Data after $48 \mathrm{~h}$ of Reperfusion

\begin{tabular}{|c|c|c|c|c|c|c|c|}
\hline & $\begin{array}{c}\text { LVSP } \\
(\mathrm{mmHg})\end{array}$ & $\begin{array}{l}\text { LVEDP } \\
(\mathrm{mmHg})\end{array}$ & $\begin{array}{c}\text { HR } \\
\text { (beats/min) }\end{array}$ & $\begin{array}{l}+\mathrm{dP} / \mathrm{dt}_{\max } \\
(\mathrm{mmHH} / \mathrm{s})\end{array}$ & $\begin{array}{l}-\mathrm{dP} / \mathrm{dt}_{\max } \\
(\mathrm{mmHH} / \mathrm{s})\end{array}$ & $\begin{array}{c}\text { SBP } \\
(\mathrm{mmHg})\end{array}$ & $\begin{array}{c}\text { DBP } \\
(\mathrm{mmHg})\end{array}$ \\
\hline Sham group $(n=10)$ & $109 \pm 6.7^{*}$ & $12.2 \pm 1.1$ & $296 \pm 33$ & $3,754 \pm 312$ & $-3,285 \pm 357$ & $106 \pm 8.9$ & $75 \pm 7.1$ \\
\hline Control group $(\mathrm{n}=10)$ & $93 \pm 6.8^{*}$ & $14.8 \pm 2.1^{*}$ & $290 \pm 24$ & $2,803 \pm 220 *$ & $-2,319 \pm 267 *$ & $90 \pm 6.9 *$ & $63 \pm 4.7^{*}$ \\
\hline Propofol group $(n=10)$ & $97 \pm 5.3^{*}$ & $13.5 \pm 2.0$ & $290 \pm 26$ & $3,240 \pm 235^{*,+, キ}$ & $-2,599 \pm 310^{*}$ & $96 \pm 4.3^{*}$ & $70 \pm 5.3$ \\
\hline Intralipid group $(n=10)$ & $93 \pm 5.1^{*}$ & $14.6 \pm 2.3^{*}$ & $284 \pm 27$ & $2,901 \pm 231 *$ & $-2,356 \pm 227 *$ & $91 \pm 5.2^{*}$ & $65 \pm 4.4^{*}$ \\
\hline
\end{tabular}

The values are mean \pm SD. n: number of rats, LVSP: left ventricular systolic pressure, LVEDP: left ventricular end diastolic pressure, HR: heart rate, $+\mathrm{dP} / \mathrm{dt}_{\max }$ : peak rate of intraventricular pressure increase, $-\mathrm{dP} / \mathrm{dt}_{\max }$ : peak rate of intraventricular pressure decrease, SBP: systolic blood pressure, DBP: diastolic blood pressure. ${ }^{*} \mathrm{P}<0.05$ compared to the sham group. ${ }^{\dagger} \mathrm{P}<0.05$ compared to the control group. ${ }^{\dagger} \mathrm{P}<0.05$ compared to the propofol group. 
Table 2. Body, Left Ventricle, Infarct Area Weight, and Infarct Area Weight as a Percentage of the Area at Risk

\begin{tabular}{lcccc}
\hline & $\begin{array}{c}\text { Sham group } \\
(\mathrm{n}=10)\end{array}$ & $\begin{array}{c}\text { Control group } \\
(\mathrm{n}=10)\end{array}$ & $\begin{array}{c}\text { Propofol group } \\
(\mathrm{n}=10)\end{array}$ & $\begin{array}{c}\text { Intralipid group } \\
(\mathrm{n}=10)\end{array}$ \\
\hline Body weight (g) & $228 \pm 8.4$ & $230 \pm 7.4$ & $227 \pm 8.5$ & $227 \pm 6.4$ \\
LV weight (g) & $0.56 \pm 0.05$ & $0.58 \pm 0.06$ & $0.58 \pm 0.07$ & $0.59 \pm 0.06$ \\
Infarct area weight (g) & & $0.12 \pm 0.05$ & $0.08 \pm 0.04^{*}$ & $0.09 \pm 0.04$ \\
Infarct area weight /area at risk (\%) & & $49.8 \pm 19.5$ & $32.6 \pm 16.6^{*}$ & $33.4 \pm 17.0^{*}$ \\
\hline
\end{tabular}

The values are mean \pm SD. $\mathrm{n}$ : number of rats, $\mathrm{LV}$ : left ventricle. $* \mathrm{P}<0.05$ compared to the control group.

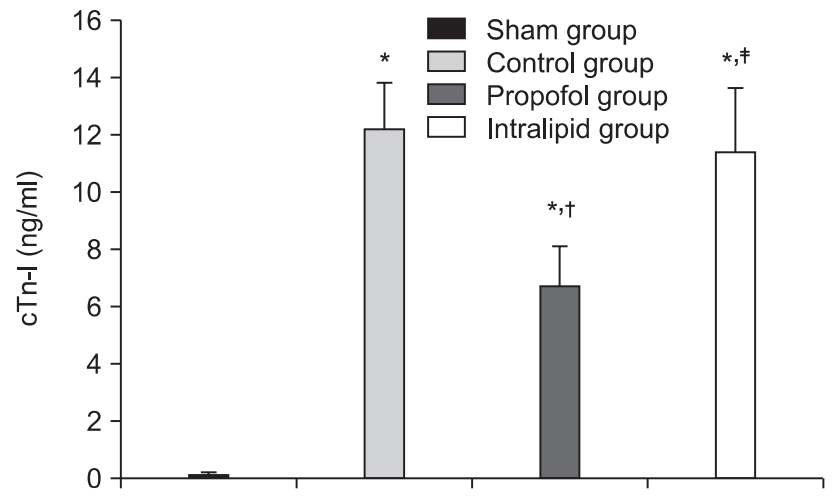

Fig. 1. Serum cTn-I levels in the different groups undergoing cardiac ischemia/reperfusion injury. The values are the mean \pm SD. cTn-I: cardiac troponin I. $* \mathrm{P}<0.05$ compared to the sham group. ${ }^{\dagger} \mathrm{P}<0.05$ compared to the control group. ${ }^{\ddagger} \mathrm{P}<0.05$ compared to the propofol group.

\section{Serum cTn-I levels}

The serum cTn-I levels in the sham, control, propofol, and intralipid groups were $0.087 \mathrm{ng} / \mathrm{ml}, 12.2 \mathrm{ng} / \mathrm{ml}(\mathrm{P}=0.0001 \mathrm{vs}$. sham group), $6.7 \mathrm{ng} / \mathrm{ml}(\mathrm{P}=0.0001$ vs. sham group, $\mathrm{P}=0.0001$ vs. control group), and $10.4 \mathrm{ng} / \mathrm{ml}(\mathrm{P}=0.0001$ vs. sham group, $\mathrm{P}=0.005$ vs. intralipid group), respectively (Fig. 1). The I/ R-induced serum cTn-I level was reduced by propofol infusion during the peri-ischemic period.

\section{Discussion}

Propofol improved myocardial contractility, reduced myocardial infarct size, and decreased serum cTn-I levels after a regional I/R injury in an in vivo rat heart model after $48 \mathrm{~h}$ of reperfusion. It has been reported that necrotic cell death reaches a peak at $24 \mathrm{~h}$, whereas apoptotic cell death in the peri-necrotic myocardium develops progressively to $72 \mathrm{~h}$ during the late reperfusion period [10]. Although many reports have addressed the myocardial protective effect of propofol, few reports have examined the long-term effects. Myocardial infarction was extended progressively; therefore, the hemodynamic parameters, infarct size, and cTn-I were measured after $48 \mathrm{~h}$ of reperfusion to identify the delayed myocardial protective effect of propofol. Propofol improved cardiac function and reduced myocardial infarct size following a regional I/R injury in an in vivo rat heart model after a 48 - $\mathrm{h}$ reperfusion.

Of the hemodynamic parameters, $+\mathrm{dP} / \mathrm{dt}_{\max }$ represents myocardial contractility, and $+\mathrm{dP} / \mathrm{dt}_{\max }$ improved significantly in the propofol group compared to the control group, indicating that the myocardial protective effect of propofol was maintained after a $48 \mathrm{~h}$ reperfusion. The effect of myocardial protection was not related to intralipids. Diastolic function is another important myocardial contractility factor, which is represented by $-\mathrm{dP} / \mathrm{dt}_{\max }$. However, in this study, $-\mathrm{dP} / \mathrm{dt}_{\max } \mathrm{did}$ not improve significantly in the propofol group compared to the control group.

Although quantitating myocardial infarct size is subjective, it is a useful means to evaluate myocardial infarct size. A prolonged reperfusion time of $24-72 \mathrm{~h}$ allows for a more precise histological quantitation of necrosis than do shorter times and excludes the possibility that an apparent reduction in infarct size observed early after the onset of reperfusion is subsequently overcome by delayed necrosis or apoptosis [14]. The infarct size was significantly smaller in the propofol and intralipid groups than in the control group, indicating that intralipid has a partial myocardial protective effect.

The role of cTn-I and cTn-T measurements in the diagnosis of patients with acute coronary syndrome is well established [15]. These measurements provide a definitive biochemical test to confirm or exclude myocardial necrosis. Troponin assays are not only more sensitive but are also more specific than a CK-MB assay. In this study, the I/R injury increased cTn-I serum levels, which were reduced by propofol infusion during the periischemic period.

This study had some limitations. First, the frequent lack of comparisons with a non-anesthetized control group is a difficulty when examining the effects of these intravenous anesthetic agents, particularly in vivo, because many studies have used acutely instrumented models requiring basal anesthesia [16-18]. Second, ketamine blocks the cardioprotective effects of ischemic preconditioning [19]. However, the effect is stereoselective, and $\mathrm{R}(-)$-ketamine mainly blocks the effects of preconditioning, whereas racemic ketamine does not $[20,21]$. Racemic ketamine was used as 
the anesthetic drug in this study because it has the lowest myocardial protective effect compared to other anesthetic drugs. Third, the hemodynamic parameters were only checked at $48 \mathrm{~h}$ after reperfusion. They could not be checked at baseline or during the ischemic period due to technical difficulties.

In conclusion, a clinically relevant propofol concentration was associated with a delayed myocardial protective effect after a regional I/R injury in an in vivo rat heart model. This myocardial protective effect might not be due to delayed myocardial injury, but to the myocardial protective effect of propofol itself.

\section{References}

1. Xia Z, Godin DV, Chang TK, Ansley DM. Dose-dependent protection of cardiac function by propofol during ischemia and early reperfusion in rats: effects on $15-\mathrm{F}_{2 \mathrm{t}}$-isoprostane formation. Can J Physiol Pharmacol 2003; 81: 14-21.

2. Javadov SA, Lim KH, Kerr PM, Suleiman MS, Angelini GD, Halestrap AP. Protection of hearts from reperfusion injury by propofol is associated with inhibition of the mitochondrial permeability transition. Cardiovasc Res 2000; 45: 360-9.

3. Kokita N, Hara A, Abiko Y, Arakawa J, Hashizume H, Namiki A. Propofol improves functional and metabolic recovery in ischemic reperfused isolated rat hearts. Anesth Analg 1998; 86: 252-8.

4. Yang CY, Wong CS, Yu CC, Luk HN, Lin CI. Propofol inhibits cardiac L-Type calcium current in guinea pig ventricular myocytes. Anesthesiology 1996; 84: 626-35.

5. Zhou W, Fontenot HJ, Liu S, Kennedy RH. Modulation of cardiac calcium channels by propofol. Anesthesiology 1997; 86: 670-5.

6. Jordan JE, Zhao ZQ, Vinten-Johansen J. The role of neutrophils in myocardial ischemia-reperfusion injury. Cardiovasc Res 1999; 43: 860-78.

7. Simpson PJ, Fantone JK, Mickelson JK, Gallagher KP, Lucchesi BR. Identification of a time window for therapy to reduce experimental canine myocardial injury: suppression of neutrophil activation during 72 hours of reperfusion. Circ Res 1988; 63: 1070-9.

8. Shin IW, Lim BW, Chung YS, Lee HM, Sohn JT, Lee HK, et al. The effect of propofol on myocardial protection after regional ischemia-reperfusion injury in an in vivo rat heart model. Korean J
Anesthesiol 2008; 55: 338-43.

9. Zhao ZQ, Nakamura M, Wang NP, Velez DA, Hewan-Lowe KO, Guyton RA, et al. Dynamic progression of contractile and endothelial dysfunction and infarct extension in the late phase of reperfusion. J Surg Res 2000; 94: 133-44.

10. Zhao ZQ, Velez DA, Wang NP, Hewan-Lowe KO, Nakamura M, Guyton RA, et al. Progressively developed myocardial apoptotic cell death during late phase of reperfusion. Apoptosis 2001; 6: 279-90.

11. Thompson K, Wisenberg G, Sykes J, Thompson RT. Similar longterm cardiovascular effects of propofol or isoflurane anesthesia during ischemia/reperfusion in dogs. Can J Anaesth 2002; 49: 978-85.

12. Murry CE, Jennings RB, Reimer KA. Preconditioning with ischemia: a delay of lethal cell injury in ischemic myocardium. Circulation 1986; 74: 1124-36.

13. Ambrosio G, Zweier JL, Becker LC. Apoptosis is prevented by administration of superoxide dismutase in dogs with reperfused myocardial infarction. Basic Res Cardiol 1998; 93: 94-6.

14. Piper HM, García-Dorado D, Ovize M. A fresh look at reperfusion injury. Cardiovasc Res 1998; 38: 291-300.

15. Babuin L, Jaffe AS. Troponin: the biomarker of choice for the detection of cardiac injury. CMAJ 2005; 173: 1191-202.

16. Ross S, Foëx P. Protective effects of anaesthetics in reversible and irreversible ischaemia-reperfusion injury. Br J Anaesth 1999; 82: 622-32.

17. Nayler WG. Basic mechanisms involved in the protection of the ischaemic myocardium: the role of calcium antagonists. Drugs 1991; 42 Suppl 2: 21-7.

18. Schlack W, Ebel D, Grunert S, Halilović S, Meyer O, Thämer V. Effect of heart rate reduction by 4-(N-ethyl-N-phenyl-amino)-1,2dimethyl-6-(methylamino) pyrimidinium chloride on infarct size in dog. Arzneimittelforschung 1998; 48: 26-33.

19. Kato R, Foëx P. Myocardial protection by anesthetic agents against ischemia-reperfusion injury: an update for anesthesiologists. Can J Anaesth 2002; 49: 777-91.

20. Molojavyi A, Preckel B, Comfére T, Müllenheim J, Thämer V, Schlack W. Effects of ketamine and its isomers on ischemic preconditioning in the isolated rat heart. Anesthesiology 2001; 94: 623-9.

21. Müllenheim J, Frässdorf J, Preckel B, Thämer V, Schlack W. Ketamine, but not $\mathrm{S}(+)$-ketamine, blocks ischemic preconditioning in rabbit hearts in vivo. Anesthesiology 2001; 94: 630-6. 